\title{
COLD AGGLUTININS. II. COLD ISOHEMAGGLUTININS IN PRIMARY ATYPICAL PNEUMONIA OF UNKNOWN ETIOLOGY WITH A NOTE ON THE OCCURRENCE OF HEMOLYTIC ANEMIA IN THESE CASES
}

\author{
By MAXWELL FINLAND, OSLER L. PETERSON, HOWARD E. ALLEN, \\ BERNARDO A. SAMPER, AND MILDRED W. BARNES \\ (From the Thorndike Memorial Laboratory, Second and Fourth Medical Services (Harvard), \\ Boston City Hospital, and the Department of Medicine, Harvard Medical School, Boston)
}

(Received for publication September 22, 1944)

In the preceding paper (1), there was presented a summary of the maximum titers of cold agglutinins found in 1069 cases of a variety of conditions, including the various infections of the respiratory tract that are commonly encountered in this vicinity. Significant titers (in dilutions greater than 20) were obtained only in cases of primary atypical pneumonia of unknown etiology, ${ }^{1}$ and in a few other cases particularly those of hemolytic anemia. The present paper is concerned solely with an analysis of the results of the tests for cold isohemagglutinins in 200 cases with characteristic clinical and $x$-ray findings of atypical pneumonia. A preliminary report of some of these findings has already been published (2).

\section{PATIENTS, MATERIALS, AND METHODS}

Selection of cases. All of the 200 cases included in this study occurred between September 1942 and January 1944, inclusive. Most of them were from among the regular admissions to the medical wards of the Boston City Hospital during this period, but 45 of them occurred in other hospitals. Almost all of the latter were seen on one or more occasions by one of the authors, and the bloods and the clinical and laboratory data were obtained and generously put at our disposal by their respective physicians. All of the cases fulfilled the criteria for the diagnosis of primary atypical pneumonia of unknown etiology $(3,4)$, including definite and characteristic $\mathbf{x}$-ray findings of involvement of at least an appreciable portion of one lobe. Doubtful cases in which either the $\mathbf{x}$-ray or clinical findings were not entirely characteristic or in which a primary bacterial or virus etiology was determined or strongly suspected, were excluded for purposes of this study. Fifteen fatal cases are included. Autopsies were obtained in most of these cases and confirmed the clinical diagnosis in each instance.

Methods. The method used in the tests for cold agglutins was given in detail in the preceding paper (1). For the present study, the specimens of venous blood were all collected under sterile precautions and the serum was separated from the clotted blood, either at room tempera-

1 Hereafter referred to for brevity as "atypical pneumonia." ture or, more often, after the blood had been kept at $37^{\circ} \mathrm{C}$. for a short while. The cleared sera were stored in rubber stoppered tubes at 5 to $10^{\circ} \mathrm{C}$. Specimens, averaging 3 per patient, were obtained at suitable intervals. The tests were carried out either on the day when the blood was obtained or within a few days. Equal volumes of serum and 2 per cent saline suspensions of 2- to 4-day-old red blood cells from individual group $\mathrm{O}$ donors were used. The titers are recorded as the reciprocals of the highest final dilutions of serum giving $1+$ agglutination at 0 to $5^{\circ} \mathrm{C}$. and complete dispersion at $37^{\circ} \mathrm{C}$.

\section{RESULTS}

The conditions under which the present cases were studied unfortunately did not permit frequent observations throughout the entire course of the acute illness and prolonged observations during convalescence in every instance. Data concerning certain of the features to be considered are, therefore, based on limited numbers of cases. In the analysis which follows, the time relationships are referred to the day of onset of symptoms. In most of the cases, this could be ascertained quite accurately, but, in a few instances, it was only approximated.

\section{Time of appearance, decline, and disappearance}

The first postitive tests (Figure 1A) were observed between the seventh and twenty-seventh days, but mostly during the second or third week. The last negative tests in the same cases were obtained before the end of the second week in all but 2 of them. The maximum titers (Figure 2) occurred mostly between the eleventh and twentyfourth days. There were a number of cases, however, in which the maximum titers were not attained until the fifth week or later, and in 4 cases, maximum titers of 40 to 160 were observed between the fourth and eighth days and lower titers obtained later. There was no definite correlation between the maximum titers and the time 
they were attained. The first significant drop from the maximum titer occurred mostly between the third and fifth weeks (Figure 1B) and cold agglutinins could no longer be found or were present in titers of 20 or less between the fourth and sixth weeks in most cases (Figure 1C). In 3 cases, however, significant titers were still present after 2 months and disappeared during the next month. Titers in representative cases are shown in Figue 3.

\section{Histories of illustrative cases}

Certain relevant features of 2 cases are shown in Figures 4 and 5. These cases were in interns on one of the medical services and one of them may have acquired his disease from the other. A summary of their histories follows.

The illness in Case 32 (Figure 4) began with malaise, chilly sensations, fever, headache, and a hard cough which increased in severity and was dry at first but later became productive of yellow mucoid sputum. The lungs were clear to physical examination and $x$-ray at the time of admission. After a week, however, showers of fine râles appeared in the left axillary region and then spread to involve the lower half of that lung. A few râles were also heard in the base of the right lower lobe at the end of the second week. X-rays showed fine mottling in the corresponding areas. Cold agglutinins were first demonstrated in the serum in the middle of the second week, rapidly reached a maximum titer, and then declined appreciably towards the end of the fourth week. Agglutinins for the indifferent streptococcus 344 (5) first appeared at the same time as the cold agglutinins and were present at the end of the fourth week. ${ }^{2}$

Case 58 (Figure 5) was that of an intern who cared for the previous patient. Sixteen days after his colleague first took sick, he began to have marked fatigue, generalized aches, fever, headache, and soreness of the eyes, followed by cough and a tightness in the chest. Physical examination on admission was negative except for the fever. The patient then had repeated chills and sweats. Showers of medium crepitant râles appeared and spread gradually to involve the entire left lung and later the right lower lobe. $\mathrm{X}$-rays showed diffuse, finely mottled densities in the corresponding areas. Fever lasted 2 weeks and the lungs then began to clear gradually and were entirely clear before the patient was discharged from the hospital. Cold agglutinins first appeared in low titer on the ninth day, reached their peak during the third week, and then dropped rapidly. Agglutinins for streptococcus 344 were found in low titer during the third week. Sulfonamide drugs were not used in this case or in the previous one.

2 The results of the agglutination tests with this strain are considered in more detail elsewhere (6).

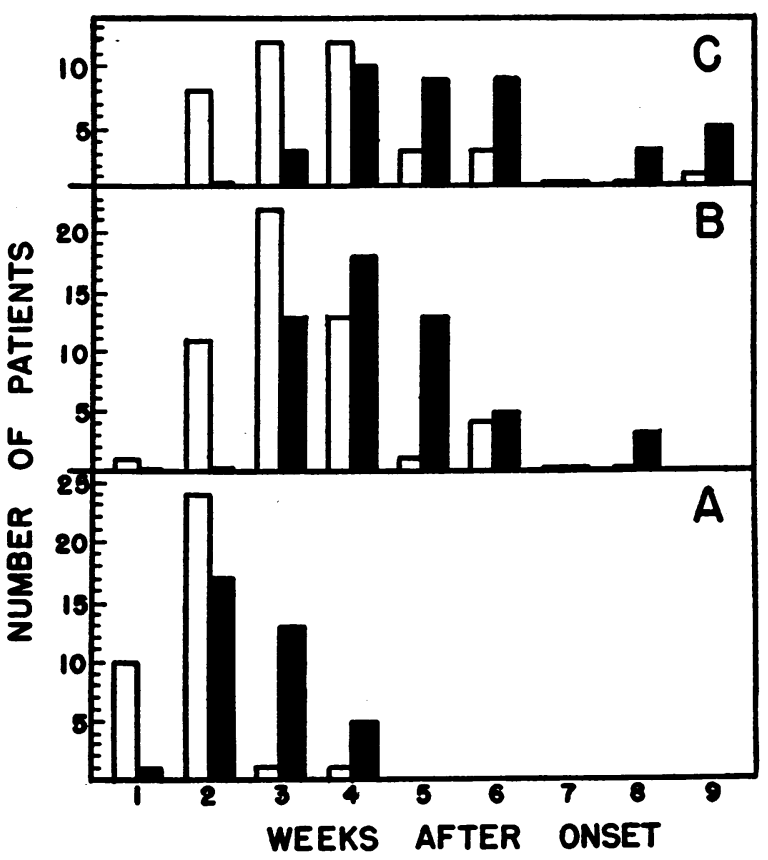

Fig. 1. Time of Appearance and Disappearance of Cold Agglutinins in Primary Atypical Pneumonia

A. First appearance ( 36 cases) : open bars = last negative test; solid bars $=$ first positive test.

B. First significant (4-fold or greater) drop in titer ( 52 cases) : open bars $=$ last observation of the maximum titer; solid bars $=$ first test after the drop in titer.

C. Disappearance (39 cases) : open bars $=$ last test before a 4-fold or greater drop in titer to 20 or less; solid bars $=$ first test in which the titer was 20 or less (the last of these includes 1 case each on days 71,87 , and 93 , respectively).

\section{Cold agglutinins in 2 cases with recurrent attacks of atypical pneumonia}

The frequency with which recurrent attacks of primary atypical pneumonia occur is difficult to determine from the available data. In several instances among the present cases, patients were admitted for more than one attack of what was diagnosed as primary atypical pneumonia, but adequate studies during each of the attacks were not made in all of these cases. Two such patients, however, were studied during both attacks and some of the relevant findings are shown in Figures 6 and 7. A resume of some of the clinical features of these cases follows:

Case 88 (Figure 6). This patient was first admitted on January 5,1943 . She had been in fairly good health until 2 weeks previously when she began to have some 


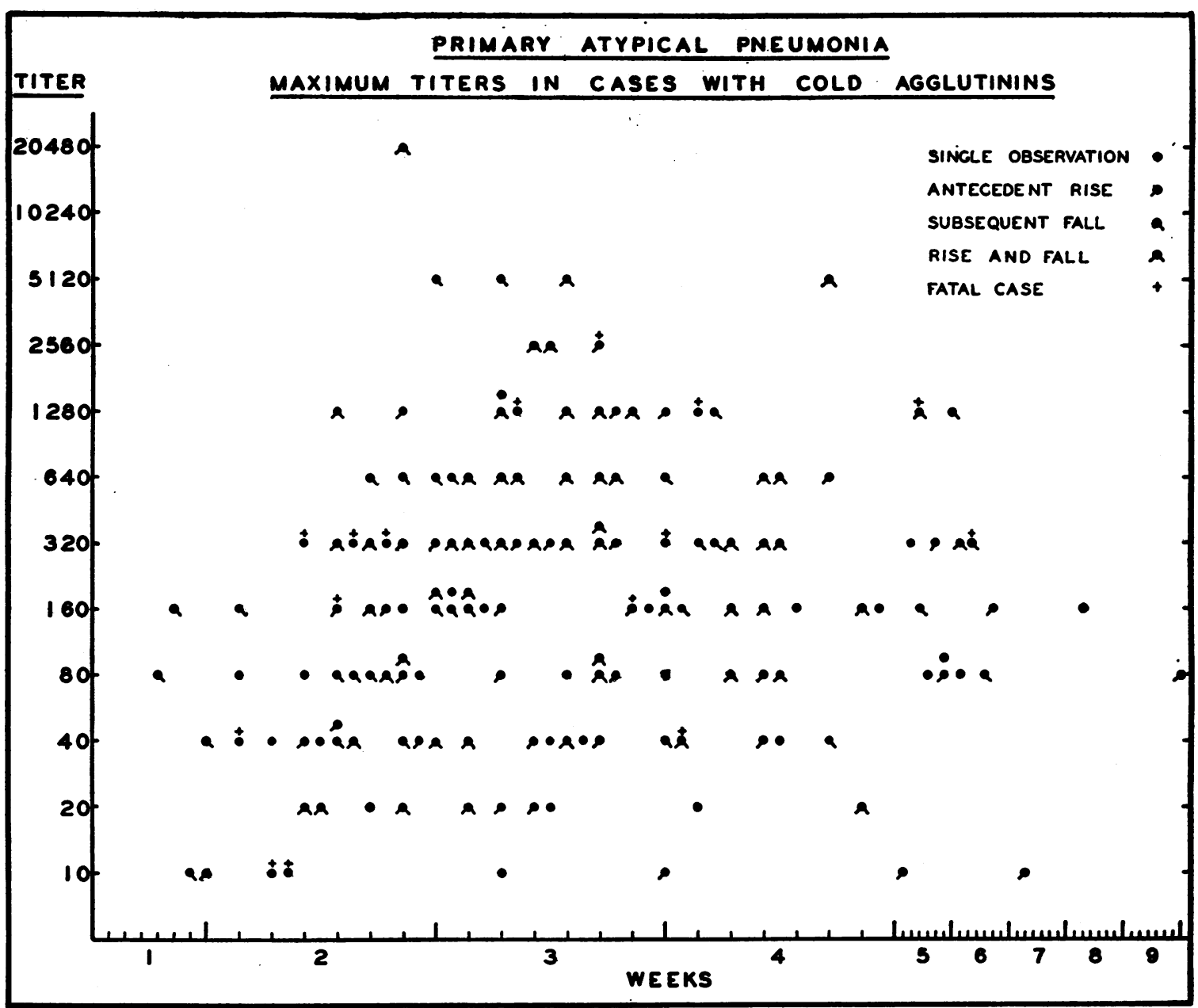

Fig. 2. Primary Atypical Pneumonia. Maximum Titers in Cases with Cold Agglutinins

Each dot represents the maximum titer of cold isohemagglutinins in one patient and the time after the onset of the disease when that titer was first demonstrated. A short line sloping up to a dot from the left indicates that observations of lower titers were made in that case before the maximum titer was obtained. A similar line sloping down to the right from the dot indicates that there were subsequent observations of lower titers. Dots without such lines indicate single observations or multiple observations of the same titer within a brief period.

malaise and vomiting. Later on the same day, and again on the following day, she had severe shaking chills. She then began to have a cough which was dry at first and later increased in severity and became productive of thick clear mucoid sputum. She rapidly developed dyspnea which increased in intensity and was associated with moderate cyanosis. Both the dyspnea and cyanosis were markedly aggravated by paroxysms of cough. At the time of admission, she appeared to be extremely dyspneic and cyanotic and showers of râles were made out in the left upper chest both anteriorly and posteriorly. There were also signs of a well developed mitral stenosis although the patient had been unaware of any heart disease. The signs in the lungs spread rapidly so that, within 2 days, râles were heard throughout the entire chest. The first x-ray on January 9th showed diffuse, finely nodular areas of density throughout both lung fields and closely resembled the radiographic picture of miliary tuberculosis. The patient was given oxygen and during the first 4 days in the hospital, she also received sulfadiazine therapy. Her course was stormy for the first week and was characterized by episodes of extreme dyspnea, cyanosis, and delirium. There was a low grade fever throughout the second week, after the temperature had been normal for 2 days. During this second week, the lungs began to clear and the patient's condition improved steadily. The lungs were essentially clear and the patient was essentially free of symptoms at the time she was discharged on January 29. Cold agglutinins appeared in low titer at the end of the first week of illness, reached a peak of 320 


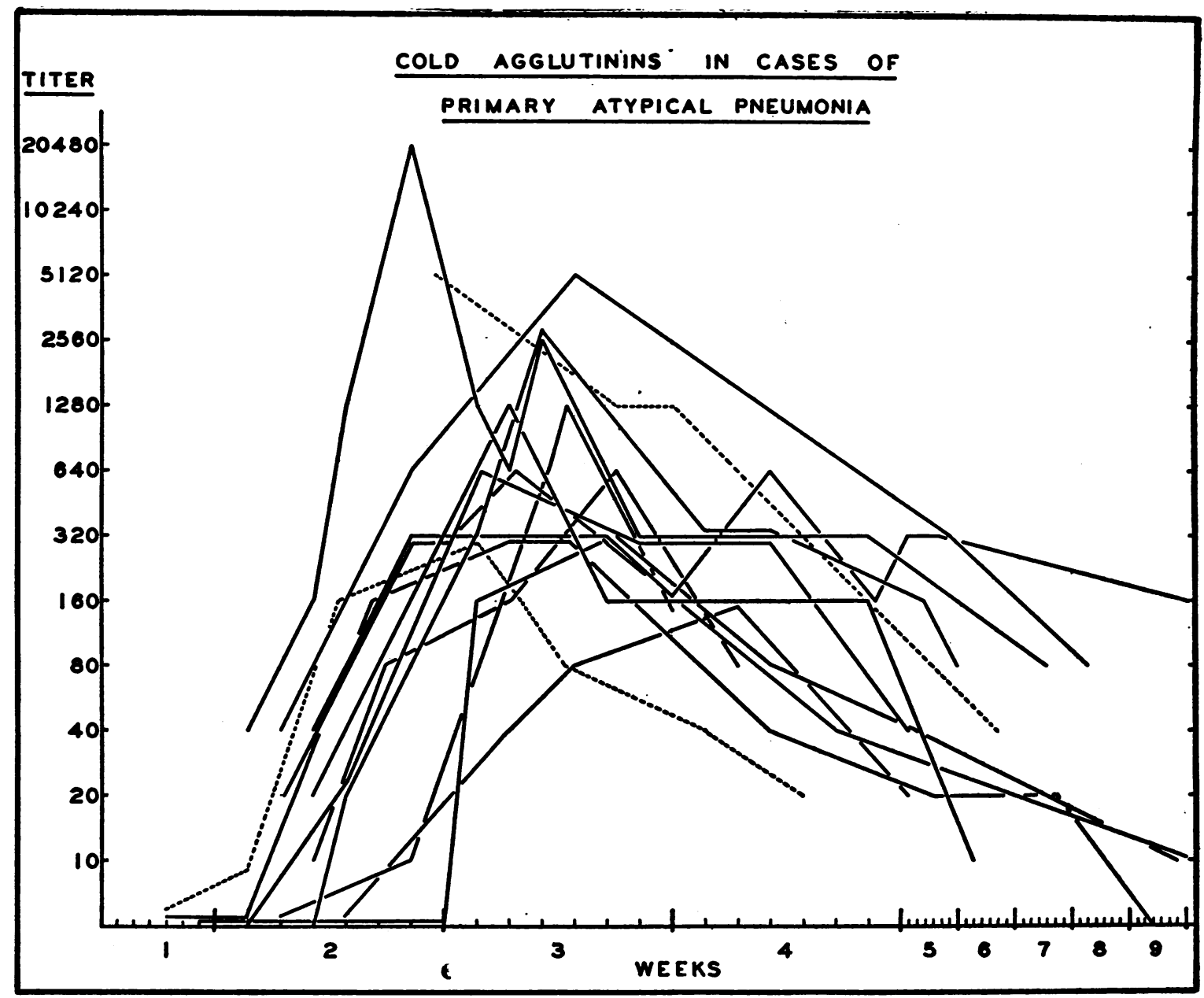

Fig. 3. Titers of Cold Isohemagglutinins in a Few Representative Cases

The dotted lines represent the observations made during 2 separate attacks in the same patient (Case 88, see Figure 5); the lower one on the left represents the titers observed during the initial attack and the upper one to the right shows the titers obtained during the recurrence.

after another week, and then declined to a level of 20 at the time of discharge. Agglutinins for streptococcus 344 were first demonstrated at the beginning of the third week in the hospital.

The patient was readmitted on November 28, 1943. During the intervening period, she had several episodes of severe dyspnea and cough associated with frequent colds. On November 18, after being free of symptoms for several weeks, she developed severe malaise, a slight sore throat, generalized aches and pains, and severe headache. She then again began to have a cough which was productive of small amounts of thick mucoid sputum. Her coughing spells again made her markedly dyspneic and cyanotic. Two days before entry she noticed a few streaks of blood in her sputum. At the time of admission, the patient appeared to be in extremis. She was markedly orthopneic and cyanotic. Loud, medium, and coarse crepitant râles resembling those of pulmonary edema were heard throughout both lungs. An $x$-ray again showed a miliary type of lesion involving most of both lung fields but this time there was slight confluence of the process in the upper part of the right lung in the first film but not in the later ones. She was again given oxygen and sulfonamide therapy for 5 days after which the temperature dropped to normal, but a low grade fever soon recurred. During the middle of the second week in the hospital, the patient developed thrombophlebitis in both lower extremities and was given a second short course of sulfonamide therapy. She again became afebrile for 2 days, after which a low grade fever again recurred. Towards the end of the fourth week in the hospital, the patient had a chill followed by a sharp rise in temperature and she began to have sharp pain in the right lower chest. A blood culture taken at the time of the chill yielded Type 8 pneu- 


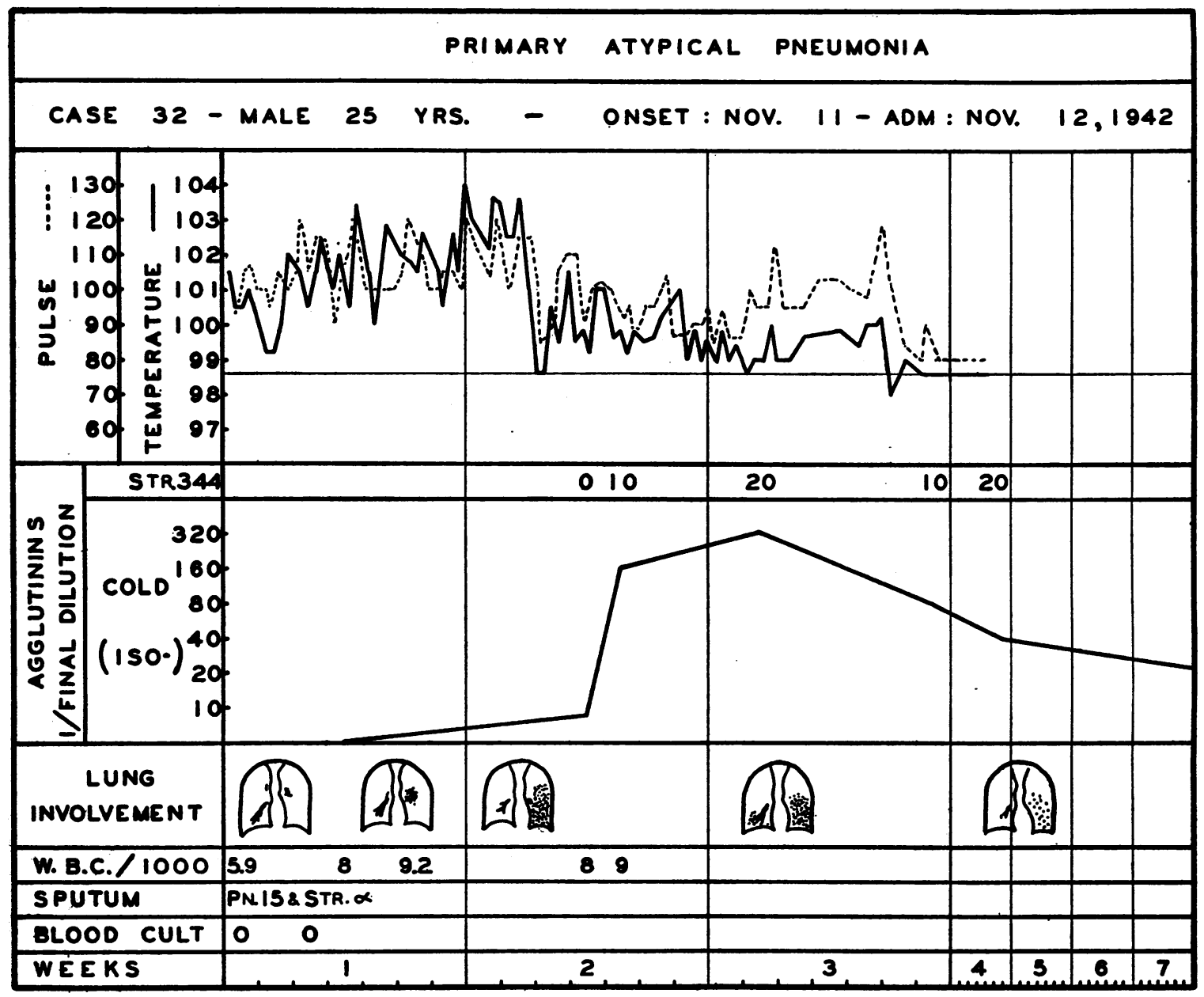

Fig. 4. Relevant Findings in a Characteristic Case of Primary Atypical Pneumonia of Moderate Severity

Note. In Figures 3 to 6 inclusive, the horizontal scale begins at the time of admission to the hospital. The following abbreviations have been used: Str. $344=$ Streptococcus 344 (the strain of anhemolytic streptococcus described by Thomas et al. (5)). Str. $\alpha=$ streptococcus with alpha hemolysis. Pn. = pneumococcus (the number represents the type). Blood Cult $\mathrm{O}=$ no growth in ordinary aerobic blood cultures. W.B.C./1000 = white blood cell count in thousands.

mococcus. Sputum was not obtained until after 2 days of sulfonamide therapy and a culture of some purulent sputum obtained at that time showed hemolytic Staphylococcus aureus as the predominant organism. The patient improved after the third day of this episode but full doses of sulfonamides were continued this time for 11 days. Signs of consolidation of the right lower lobe were found by physical examination and $x$-ray during this episode. The patient improved and the lungs cleared completely before she was discharged on January 4, 1944. Blood was first obtained for cold agglutinins at the end of the second week of this attack and a titer of 5120 was found at that time. Thereafter, the titer dropped gradually to 80 in the course of the next 4 weeks. Agglutinins for streptococcus 344 were found in the first blood in a titer of 80 but none were demonstrated in later specimens.
Case 102 (Figure 7). The first admission in this case was on April 11, 1943. Ten days previously, this patient began to have anorexia, alternating fever, chilly sensations, and prostration. On the next day, he had severe frontal headache and slight sore throat. His physician prescribed sulfadiazine which he took for 4 days without affecting his symptoms or fever. At the time of admission, he was only moderately ill without dyspnea or cyanosis. There were some patchy ulcerations on his tonsils and fine diffuse injections of his throat. He coughed frequently and raised scanty amounts of thick gray mucoid sputum. Showers of medium crepitant râles were heard over the middle of the left chest anteriorly and in the axillary region on the same side. An $x$-ray taken at this time showed a finely mottled infiltration of the middle half of the left lung field. The patient continued to have 


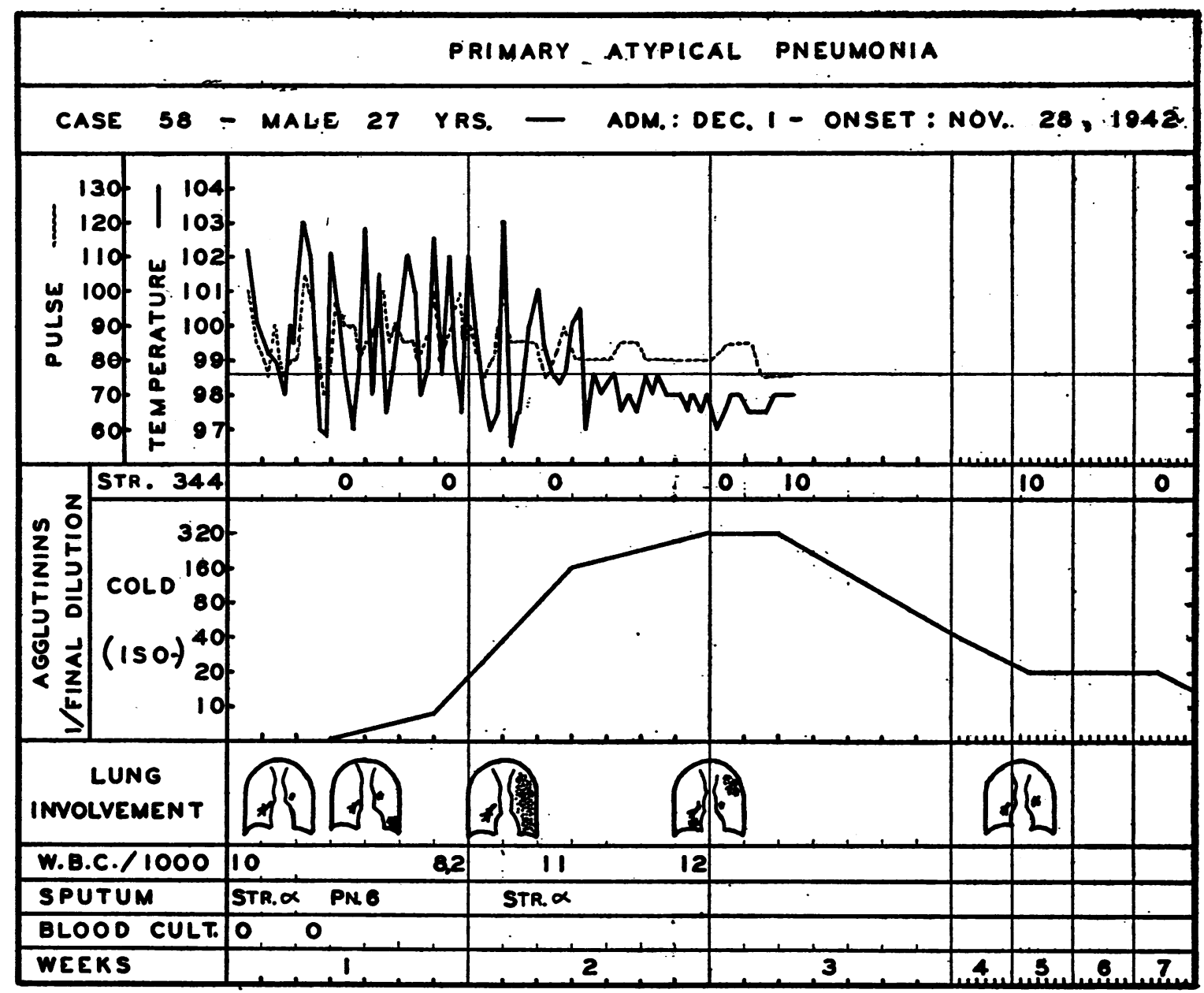

Fig. 5. Relevant Features of the Course in a Characteristic Case of Primary Atypical Pneumonia of AVErage Severity

The patient had been intimately exposed to the one whose course is shown in Figure 4 (see note under Figure 4).

fever and severe cough during the first 4 days in the hospital. The fever then subsided and the cough improved gradually although the pulmonary process extended to involve a large part of the right lower lobe. The clinical condition of the patient, however, continued to improve and the lungs were entirely clear at the time of discharge. Cold agglutinins in a titer of $\mathbf{4 0}$ were found in the first blood taken on the day after admission which was the eleventh day of the disease. The maximum titer during this admission was 640 and was obtained one week later after which the titer dropped steadily to a level of 40 at the time of discharge. Agglutinins for streptococcus 344 were not demonstrated in the first blood but were found in a titer of $\mathbf{4 0}$ during the next 2 weeks. This patient was a pigeon fancier and he had raised pigeons for some time prior to this illness. He was, therefore, suspected of having ornithosis. All of the samples of his serum were sent to Dr. Karl F. Meyer for complement fixation tests with psittacosis virus. The tests were entirely negative.
The second admission of this patient was on October 17, 1943. He had been perfectly well from the time of discharge until October 3 when he suddenly began to have a severe hacking cough productive of thick yellow mucoid sputum. Shortly thereafter, he developed substernal soreness and a sense of oppression in the chest, particularly associated with coughing. He also had a slight sore throat and headache. Two days before entry, he began to have chilly sensations, generalized aches, malaise, slight nausea, and an increase in his fever. The physical examination and $x$-ray of his lungs at this time were essentially the same as those found at the time of earlier admission, except that a few râles were heard in the right lung at this time. His lesion extended to involve most of the right lower lobe. He received sulfonamide therapy during the first 6 days in the hospital. His fever subsided on the third day and his lungs began to clear by the end of the first week in the hospital. At no time did he appear very ill nor did he have any dyspnea or cyanosis. 


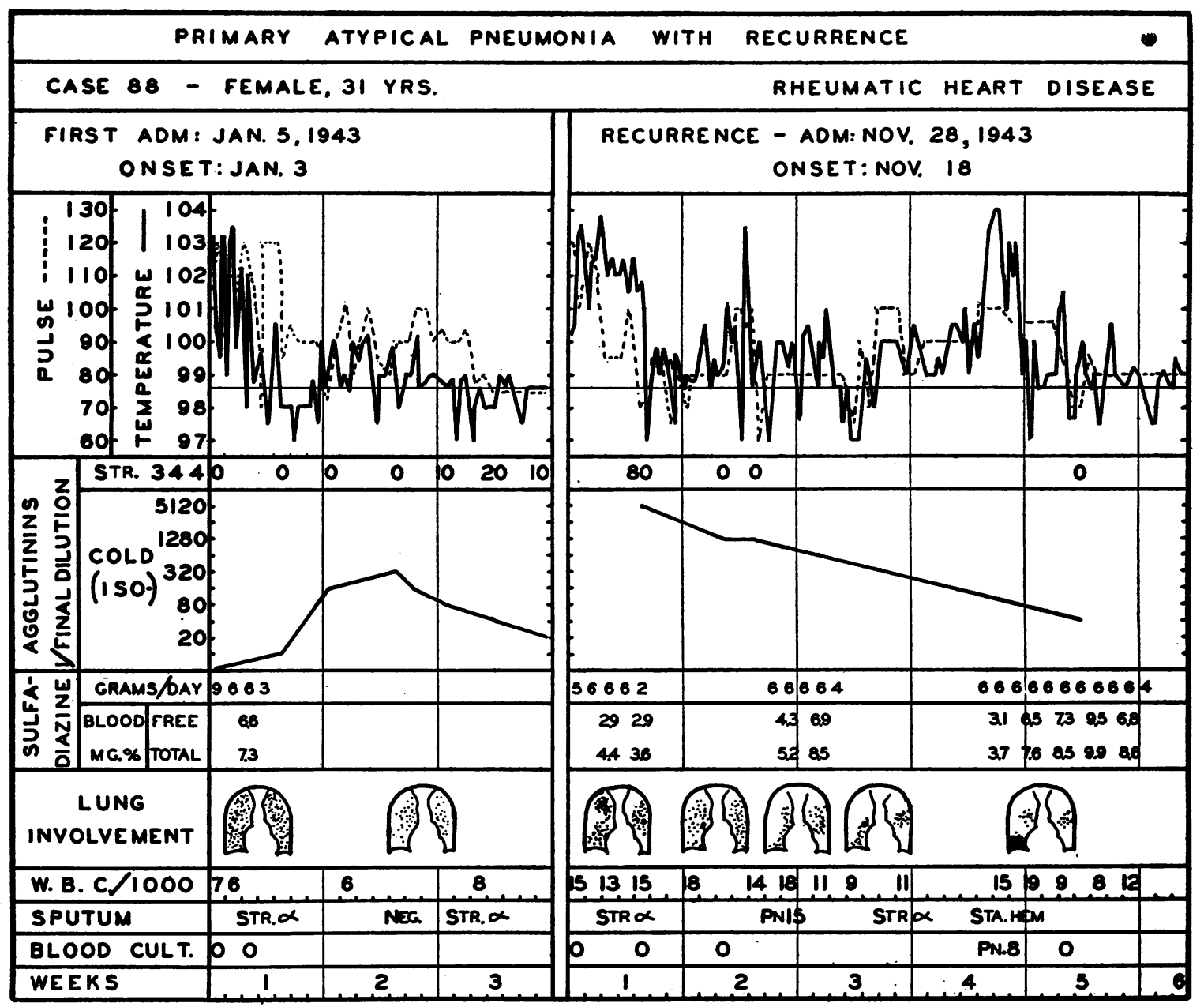

Fig. 6. Relevant Findings in the Course of 2 Attacks of Primary Atypical Pneumonia in a Patient with Rheumatic Heart Disease and Mitral Stenosis

There were no complications during the first attack. In the recurrent attack, the patient had bilateral thrombophlebitis of the legs during the second and third hospital weeks and Type 8 pneumococcal pneumonia, probably following a pulmonary infarct, during the latter half of the fourth week in the hospital (see note under Figure 4).

At the time of discharge, his lungs were entirely clear. Cold agglutinins were not found in his blood at the time of admission which was considered to be the fourteenth day of his illness. They appeared in comparatively low titer during the next 10 days and again dropped off in the following week. Agglutinins for streptococcus 344 were present in all specimens tested.

\section{Factors influencing the occurrence and titers of cold agglutinins}

These last cases and the 2 previous ones serve to illustrate what has already been said about the appearance and course of the cold agglutinins in most of the cases of atypical pneumonia. The impression was gained in the course of observing the patients that the occurrence of cold agglutinins and the height to which the titers rose was related to the severity of the disease. On the other hand, observations in a number of individual cases did not seem to bear this out. It was of interest, therefore, to analyze the data further with reference to the relation of the occurrence and maximum titers of cold agglutinins to some of the important factors in the disease. First, an attempt was made to correlate the maximum titers with the general impression of the severity of each case as it was gathered from a study of the course and 


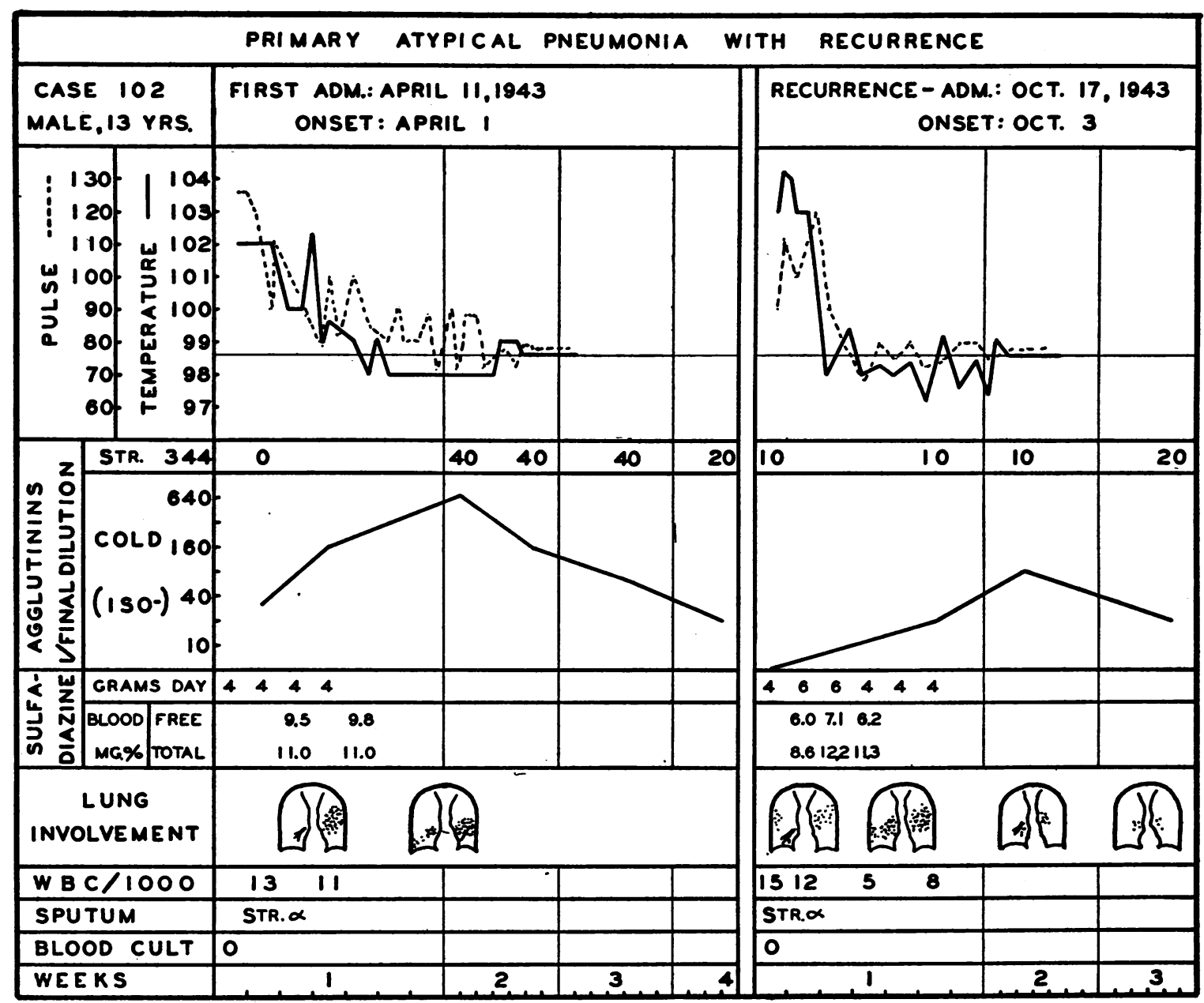

Fig. 7. Relevant Features of the Course in 2 Attacks of Atypical Pneumonia in the Same Patient There were no complications in this case (see note under Figure 4).

symptoms and all other available data. More detailed analyses were also made of specific features of the disease such as the extent of the pulmonary lesion, the height and duration of the fever, the leukocyte count, the age of the patient, and the administration of sulfonamide drugs.

Severity of the disease. Based on the clinical findings, an arbitrary grading of severity from I to $\mathrm{V}$ was given to each case. While it may be difficult to compare these grades accurately with the severity of the cases reported by others, this grading will serve to compare the relative severity in the different groups of cases in the present study. Roughly, Grade I corresponds to the severity of the large majority of the cases which have been reported by observers among ado- lescents and young adults in schools, colleges, and most military hospitals. Grades II and III correspond to the severe or the moderately severe among those cases. Grades IV and V represent the severest types of cases. The relation of the severity of the disease thus graded to the occurrence and the maximum titers of cold agglutinins is shown in Table I.

The 45 cases in which cold agglutinins could not be demonstrated and the 18 in which they were found in a titer of only 10 or 20 include most of the cases in which studies were inadequate. In about two-thirds of them, there were no observations between the 12th and 30th day of the disease. Since cold agglutinins may make their first appearance after the 12th day and may 
TABLE I

Primary atypical pmeumonia. Relation of cold isohemagglutinin titer to the severity

of the disease

\begin{tabular}{c|c|c|r|r|r|r|r}
\hline \hline \multirow{2}{*}{$\begin{array}{c}\text { Grade } \\
\text { of } \\
\text { severity }\end{array}$} & \multicolumn{5}{|c|}{ Maximum cold agglutinin titer } & Totals \\
\cline { 2 - 6 } & $\begin{array}{c}\text { Less } \\
\text { than 10 }\end{array}$ & $10-20$ & $40-80$ & $\begin{array}{c}160- \\
320\end{array}$ & $\begin{array}{c}640- \\
1280\end{array}$ & $\begin{array}{c}2560 \text { or } \\
\text { higher }\end{array}$ & \\
\hline I & $26(20)$ & $5(2)$ & 4 & 4 & 0 & 0 & 39 \\
II & $3(3)$ & $5(3)$ & 15 & 9 & 2 & 0 & 34 \\
III & $9(8)$ & 6 & 20 & 18 & 7 & 1 & 61 \\
IV & $6(5)$ & 1 & 3 & 15 & 14 & 2 & 41 \\
V-R & 0 & 0 & 2 & 2 & 2 & 4 & 10 \\
V-D & $1(1)$ & $1(1)$ & 2 & 7 & 3 & 1 & 15 \\
\hline Totals & $45(37)$ & $18(6)$ & 46 & 55 & 28 & 8 & 200 \\
\hline
\end{tabular}

$\mathrm{R}=$ Recovered. $\quad \mathrm{D}=$ Died.

Parentheses enclose the number of cases with titers less than 20 in which no observations were made between the 12 th and 30th day of the disease.

reach low levels by the end of the fourth week after higher levels had been reached earlier, it cannot be said for certain that these patients did not have cold agglutinins during that interval. Omitting these cases, there were only 6 of Grade I severity without cold agglutinins and 3 with a maximum titer of 10 or 20 . Similarly, among the cases of Grades II, III, and IV combined, there were only 2 without cold agglutinins and 9 in which the highest titer was only 10 or 20 . Among the fatal cases, the last observation was made on the fifth day in the case without cold agglutinins and on the ninth day in the one with the cold agglutinin titer of 10 .

Allowing for these facts and for the probability that most of the deaths occurred before the maximum titers could be attained, there is a definite correlation between the severity of the disease and the maximum observed cold agglutinin titer. The greater the severity of the disease, the greater is the proportion of cases in which the cold agglutinin titer reached high levels. Omitting fatal cases, titers of 640 or higher were not observed in any of the cases of Grade I severity; and were demonstrated in $6,13,39$, and 60 per cent of those of Grades II, III, IV, and V, respectively.

Extent of the pulmonary lesion. In most of the cases, the severity of the symptoms were largely dependent on the amount of lung involved, but there were many discrepancies. The relation of the maximum titer of cold agglutinins to the amount of lung involved, as estimated from the physical and $x$-ray findings, is shown in Table II. There was a close though not complete correlation between the number of lobes involved and the maximum observed cold agglutinin titers.

The case reported by another worker (7) is of interest in this connection. In that case, the symptoms were those of a very severe atypical pneumonia without abnormal physical signs and with $\mathrm{x}$-ray findings consistent with tracheobronchitis, but no areas of consolidation or infiltration were noted. High titers of cold agglutinins were noted on the 15 th to the 23 rd days. Other authors (15) also found a titer of 1000 in a girl who had a severe cough but was afebrile and ambulatory and had a negative $\mathbf{x}$-ray.

Age. From the fact that most of the early reports concerning the disease now generally recognized as primary atypical pneumonia were from

TABLE II

Primary atypical pneumonia. Relation of the cold
isohemagglutinin titer to the extent of the pulmonary lesion

\begin{tabular}{c|c|c|c|c|c|c|c}
\hline \hline \multirow{2}{*}{$\begin{array}{c}\text { Number } \\
\text { of lobes } \\
\text { involved }\end{array}$} & \multicolumn{5}{|c|}{ Maximum cold agglutinin titer } & Totals \\
\cline { 2 - 7 } & $\begin{array}{c}\text { Less } \\
\text { than 10 }\end{array}$ & $10-20$ & $40-80$ & $\begin{array}{c}160- \\
320\end{array}$ & $\begin{array}{c}640- \\
1280\end{array}$ & $\begin{array}{c}2560 \text { or } \\
\text { higher }\end{array}$ & \\
\hline $\begin{array}{c}\text { 1 or less } \\
2\end{array}$ & 19 & 7 & 12 & 15 & 4 & & 57 \\
3 & 20 & 7 & 15 & 18 & 5 & 2 & 67 \\
4 & 4 & 2 & $13^{1}$ & $7^{1}$ & $7^{1}$ & 1 & $34^{3}$ \\
5 & 21 & 1 & 1 & 2 & 3 & 7 & 7 \\
& 11 & $5^{1}$ & $13^{6}$ & $9^{2}$ & $5^{1}$ & $35^{12}$ \\
\hline Totals & $45^{1}$ & $18^{1}$ & $46^{2}$ & $55^{7}$ & $28^{3}$ & $8^{1}$ & $200^{15}$ \\
\hline
\end{tabular}

Superscripts denote number of fatal cases included.

schools and military hospitals, the impression generally prevails that the disease is limited in its occurrence to adolescents and young adults. In the present series, to be sure, there was a predominance of cases in young adults but there was also an appreciable number in persons over 40 and, indeed, over 60 years of age. Since, in other kinds of pneumonia, the severity of the disease, at least as judged from case fatality rates, is usually closely related to the age of the patients, it was of interest to see whether the cold agglutinin titers in the present series of cases were related to this factor. The data are shown in Table III and indicate no definite correlation between the age of the patients and the maximum cold agglutinin titers. 
It is interesting to note in passing that there was a steady increase in mortality in the increasing age groups. The rise in mortality for each decade, however, was far less than that which is usually observed in cases of bacterial pneumonia.

Height and duration of fever. The relation of these findings to the maximum cold agglutinin titers is shown in Table IV. The highest temperatures for purposes of this table, were recorded on more than one day, or at least for several readings throughout a single day, during the primary disease, and without relation to complicating bacterial infections. If those cases are excluded in which cold agglutinins were not demonstrated -and this seems reasonable from what has already been said-there appears to be a definite relation between the maximum temperatures and the cold agglutinin titers. The higher the temperatures, the greater was the proportion of cases with high cold agglutinin titers. Likewise, the higher the maximum cold agglutinin titers, the greater was the proportion of cases in which the higher temperatures were attained. There is a closer correlation, however, between the duration of the fever and the maximum cold agglutinin titers observed. The longer the fever persisted, the greater was the proportion of cases having high titers, but this was less striking in cases with fever of more than 3 weeks' duration.

Leukocyte counts. The relation of the leukocyte counts to the maximum cold agglutinin titers observed is also shown in Table IV. In about one-half of the cases, the leukocyte counts were essentially normal or only slightly elevated (7500 and 12,500). In most of the remaining cases, they remained below 7500 throughout most of the febrile course and in only 19 cases were counts above 12,500 observed during the acute disease. In many cases, particularly in severe ones, the count rose from low or normal levels to higher ones, usually during the latter part of the illness.

Omitting the cases without cold agglutinins, there is a definite though not very close relation between the level of the leukocyte counts and the maximum observed cold agglutinin titers. The higher the leukocyte count, the greater was the proportion of cases with high cold agglutinin titers. Rises in the counts were noted more often among the cases with high cold agglutinin titers.
TABLE III

Primary atypical preumonia. Relation of the cold isohemagglutinin titer to the age of the patient

\begin{tabular}{c|c|c|c|c|c|c|c}
\hline \hline \multirow{2}{*}{$\begin{array}{c}\text { Age } \\
\text { group } \\
\text { years) }\end{array}$} & \multicolumn{5}{|c|}{ Maximum cold agglutinin titer } & Totals \\
\cline { 2 - 7 } & $\begin{array}{c}\text { Less } \\
\text { than 10 }\end{array}$ & $10-$ & $40-$ & $160-$ & $640-$ & 2560 or & \\
\hline 19 or less & 8 & 6 & 18 & 13 & $11^{1}$ & 1 & $57^{1}$ \\
20 to 29 & 8 & 5 & $15^{2}$ & $17^{1}$ & 5 & & $50^{3}$ \\
30 to 39 & $13^{1}$ & 3 & 5 & $11^{2}$ & 9 & 4 & $45^{3}$ \\
40 to 49 & 10 & $2^{1}$ & 7 & $4^{2}$ & $2^{1}$ & 2 & $27^{4}$ \\
50 to 59 & 4 & 1 & & 5 & $1^{1}$ & $1^{1}$ & $12^{2}$ \\
60 or more & 2 & 1 & 1 & $5^{2}$ & & & $9^{2}$ \\
\hline Totals & $45^{1}$ & $18^{1}$ & $46^{2}$ & $55^{7}$ & $28^{3}$ & $8^{1}$ & $200^{16}$ \\
\hline
\end{tabular}

Superscripts denote number of fatal cases included.

Sulfonamide therapy. There are several reports of acute hemolytic reactions associated with sulfonamide therapy ( 8 to 11 ). Sulfadiazine and sulfathiazole were the drugs implicated in recent cases, but such reactions were more frequent in sulfanilamide-treated cases. The case histories in many instances were quite characteristic of atypical pneumonia but data are not available concerning cold agglutinins in the blood before the development of the anemia. There are, however, reports of anemia and cold autohemagglutinins occurring in pneumonia without relation to sulfonamide therapy $(12,13)$.

The cases of the present series are listed in Table IV according to the amounts of sulfonamide therapy administered during the acute disease. One-fourth of all the cases received no sulfonamide at all throughout the course of their illness. In the remaining cases, varying amounts were given either because of the failure of the patients' fever and symptoms to improve or because bacterial complications were demonstrated or suspected. There was no striking difference between the distribution of the maximum titers of cold agglutinins in those cases in which various amounts of sulfonamides were used as compared with those in which such drugs were withheld. Furthermore, many of the high titers were obtained before sulfonamide therapy was started.

Time when the cases occurred. It was of interest to see whether cold agglutinins were encountered more often or in higher titers at one time of the year as compared with another. The numbers of cases observed each month are shown in Figure 8 and the maximum titers are appro- 
TABLE IV

Primary atypical pneumonia. Relation of maximum cold isohemagglutinin titer to the height and duration of fever, to the leukocyte count, and to sulfonamide therapy

\begin{tabular}{|c|c|c|c|c|c|c|c|}
\hline Maximum titer & Less than 10 & $10-20$ & $40-80$ & $160-320$ & $640-1280$ & 2560 or higher & Totals \\
\hline $\begin{array}{l}\text { Maximum temperature } \\
\text { Less than } 101^{\circ} \mathrm{F} \text {. } \\
101 \text { to } 102.9 \\
103 \text { or higher }\end{array}$ & $\begin{array}{r}15 \\
6 \\
24\end{array}$ & $\begin{array}{r}5 \\
2 \\
11\end{array}$ & $\begin{array}{r}7 \\
14 \\
25\end{array}$ & $\begin{array}{l}13 \\
18 \\
24\end{array}$ & $\begin{array}{r}3 \\
5 \\
20\end{array}$ & $\begin{array}{l}0 \\
1 \\
7\end{array}$ & $\begin{array}{r}43 \\
46 \\
111\end{array}$ \\
\hline Totals & 45 & 18 & 46 & 55 & 28 & 8 & 200 \\
\hline $\begin{array}{c}\text { Duration of fever } \\
7 \text { days or less } \\
8 \text { to } 14 \text { days } \\
15 \text { to } 21 \text { days } \\
22 \text { or more days }\end{array}$ & $\begin{array}{r}18 \\
15 \\
6 \\
6\end{array}$ & $\begin{array}{r}2 \\
11 \\
5 \\
0\end{array}$ & $\begin{array}{r}5 \\
25 \\
10 \\
6\end{array}$ & $\begin{array}{r}1 \\
22 \\
25 \\
7\end{array}$ & $\begin{array}{r}0 \\
4 \\
19 \\
5\end{array}$ & $\begin{array}{l}0 \\
2 \\
4 \\
2\end{array}$ & $\begin{array}{l}26 \\
79 \\
69 \\
26\end{array}$ \\
\hline Totals & 45 & 18 & 46 & 55 & 28 & 8 & 200 \\
\hline $\begin{array}{l}\text { Leukocyte count } \\
\text { Less than } 7500 \\
7500 \text { to } 12,500 \\
12,600 \text { or more }\end{array}$ & $\begin{array}{l}22 \\
18(8) \\
5(6)\end{array}$ & $\begin{array}{c}8 \\
10(1) \\
0(4)\end{array}$ & $\begin{array}{l}20 \\
22(9) \\
4(9)\end{array}$ & $\begin{array}{l}17 \\
33(11) \\
5(8)\end{array}$ & $\begin{array}{c}7 \\
18(2) \\
3(8)\end{array}$ & $\begin{array}{l}2 \\
4 \\
2(4)\end{array}$ & $\begin{array}{c}76 \\
105(31) \\
19(39) \\
\end{array}$ \\
\hline Totals & 45 & 18 & 46 & 55 & 28 & 8 & 200 \\
\hline $\begin{array}{l}\text { Sulfonamide therapy } \\
\text { None } \\
5 \text { to } 20 \text { grams } \\
21 \text { to } 40 \text { grams } \\
41 \text { or more grams }\end{array}$ & $\begin{array}{r}18 \\
5 \\
14 \\
8\end{array}$ & $\begin{array}{l}3 \\
4 \\
6 \\
5\end{array}$ & $\begin{array}{l}11 \\
10 \\
13 \\
12\end{array}$ & $\begin{array}{l}15 \\
14 \\
14 \\
12\end{array}$ & $\begin{array}{r}3 \\
4 \\
14 \\
7\end{array}$ & $\begin{array}{l}2 \\
3 \\
3\end{array}$ & $\begin{array}{l}50 \\
39 \\
64 \\
47\end{array}$ \\
\hline Totals & 45 & 18 & 46 & 55 & 28 & 8 & 200 \\
\hline
\end{tabular}

Parentheses enclose the numbers of additional cases in whom leukocyte counts reached these levels late in the course of the illness after previous lower counts.

piately indicated in each instance. There was no definite correlation between the maximum titers and the time when the cases occurred.

The monthly incidence of cases may be noted in passing. There were 2 waves: the first and larger of them in the fall and winter of 1942-43 and the smaller during the same season of the following year. Deaths were most frequent in October 1942. Characteristic cases of primary atypical pneumonia were rarely encountered during the epidemic of influenza which reached its peak in December 1943 or in the months which followed. Similar curves of incidence have been noted by other workers during the same period.

Some of the more important relationships which have been discussed are summarized in Table V. Briefly, the maximum cold agglutinin titer is related quite closely to the general severity of the symptoms, to the number of lobes involved, and to the duration of fever. Less striking is its relation to the height of the fever and to the leukocyte count. There is no correlation between the cold agglutinin titer and the age of the patient, the administration of sulfonamides, or the time when the cases occurred.

Hemolytic anemia in atypical pneumonia and its relation to cold agglutinins and to sulfonamide therapy

The original observations concerning the occurrence of cold agglutinins in atypical pneumonia were made in September 1942 following the occurrence, in rapid succession, of 2 cases of acute hemolytic anemia. Both of them were extremely ill and their entire lungs were involved. In one of them, sulfathiazole and sulfadiazine had been given for several days before the anemia was recognized; in the other, there was marked anemia before the first and only dose of sulfadiazine was given. In each instance, the presence of cold agglutinins was first indicated by diffculties in blood grouping and cross matching preliminary to transfusion and also was indicated by the appearance of clumping during red blood cell 


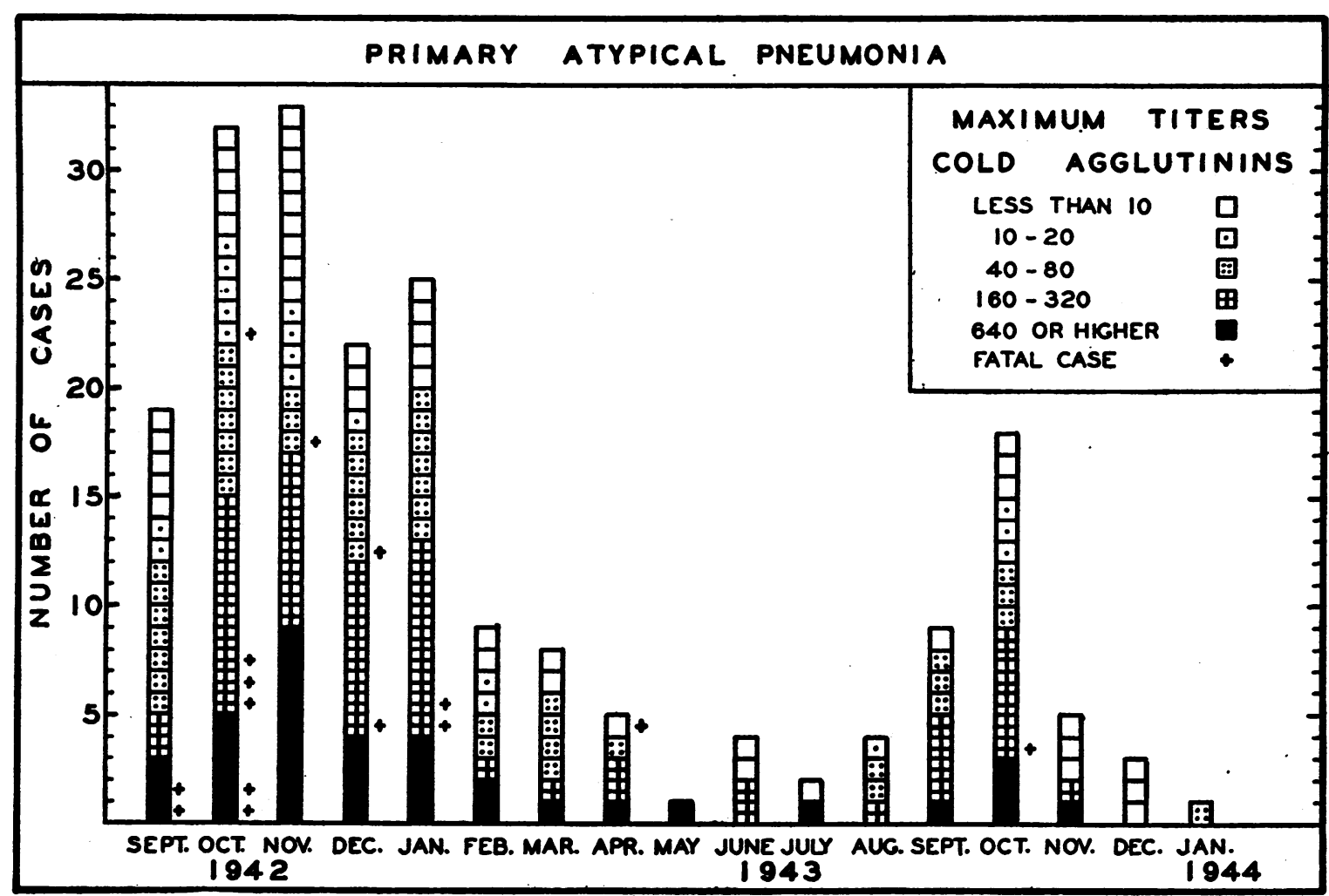

Fig. 8. The Monthly Occurrence of the 200 Characteristic Cases of Primary Atypical Pheumonia INCLUded IN This Study

Each square represents a single case and the cold isohemagglutinin titer is appropriately designated.

counts. In the first of these cases, the titer of cold agglutinins tested with the cells of another group $\mathrm{O}$ donor was 640 . This test was done at least 3 days after the anemia had developed, and sulfadiazine was still being given. In the second patient, there was no opportunity to do such quantitative studies and this case is not included in the present series. Both of these patients died, the first one several days after the anemia was recognized and the other after only a few hours. Autopsies were done in both cases and revealed characteristic pulmonary lesions which will be described elsewhere.

In the present series, there were a total of 11 cases in which various degrees of anemia were demonstrated. Most of the severe ones were first recognized only after the anemia was well established so that accurate observations concerning the development of this condition were not available. A few relevant observations which are available in these cases will be noted. More de- tailed studies concerning the mechanism of anemia were made in some of the cases by Dr. T. $H$. Ham and Miss Geneva A. Daland but these are not included here.

In 2 cases, a drop in hemoglobin of 15 to 20 per cent was demonstrated. In one of them, the drop occurred early in the third week of the disease during the first days of sulfadiazine therapy and the drug was continued without aggravating the anemia appreciably. In the second, the anemia developed 1 week after sulfadiazine therapy was stopped. In the former, the cold agglutinin titer was 4096 and in the latter 5120 , both being noted at the height of the disease. These titers dropped in both instances to a level of 80 over the following 6 weeks.

In 5 cases, a drop in hemoglobin of between 20 and 40 per cent was noted. In 3 of them, the anemia was fully developed by the end of the second week of the disease and sulfonamide therapy was started later. The blood hemoglobin increased during this treatment. In the other 2 cases, the anemia occurred during the course of sulfonamide therapy: in one case, in the second week, and in the other, during the fourth week of the disease. In these patients, also, the sulfonamide therapy was continued after the anemia occurred, and the hemoglobin levels rose in 
TABLE V

Primary atypical pneumonia. Summary of some factors influencing the cold isohemagglutinin titer

\begin{tabular}{l|c|c|c|c|c|c|c|}
\hline \hline \multicolumn{1}{c|}{ Maximum cold agglutinin titer } & Less than 10 & $10-20$ & $40-80$ & $160-320$ & $640-1280$ & 2560 or higher & Totals \\
\hline Number of cases * & 45 & 18 & 46 & 55 & 28 & 8 \\
\hline Severity, III to V & 36 & 44 & 59 & 76 & 93 & 100 \\
4 or 5 lobes involved & 4 & 11 & 13 & 27 & 46 & 63 \\
Temperature 101 ${ }^{\circ}$ F. or higher & 67 & 72 & 85 & 76 & 89 & 100 & 74 \\
Fever 15 days or longer & 27 & 28 & 35 & 58 & 86 & 75 & 48 \\
Leukocytes, <7500 & 49 & 44 & 43 & 31 & 25 & 25 & 38 \\
Sulfonamide therapy & 60 & 83 & 76 & 73 & 89 & 100 & 75 \\
Age, 30 years or older & 64 & 39 & 28 & 45 & 43 & 88 & 52 \\
\hline
\end{tabular}

* Figures below this line are percentages of these numbers.

spite of that fact. Sulfadiazine was the drug used in 4 of these cases and sulfathiazole was used in the fifth. In 2 of the cases, the titer of cold isohemagglutinins was only 40 shortly after the anemia was recognized. In the third case, the titer was 320, and in the fourth 640 .

In one of the patients, cold agglutinins could not be demonstrated in many specimens of serum by the usual method, that is, with the red blood cells from another group $\mathrm{O}$ donor. There was, however, definite and quite marked autoagglutination demonstrated in the cold and this was reversible on warming. This was noted in the clumps of erythrocytes seen during the blood counts and also in the whole oxalated blood which showed the red blood cells agglutinated as a hard single mass when removed from a refrigerator and a normal suspension of the red cells when the same blood was warmed in an incubator. The titer of autoagglutinins, however was not quantitated. Agglutinations were done with erythrocytes from several group $O$ donors and were all negative. This case may, therefore, represent an instance in which there were cold autohemagglutinins without cold isohemagglutinins. It is possible also, that, in some of the other cases, the autohemagglutinin titers may have been considerably higher than the titers demonstrated with another donor's cells. In a few other sera in this study and in 7 of Turner's (14), the results of the 2 tests were in essential agreement.

In the 4 remaining patients, the anemia was severe and the hemoglobin dropped 40 to 70 per cent in each case. This usually occurred over a period of 3 days or less. In 1 of the cases, the anemia was first recognized during the second week of the pneumonia and the cold isohemagglutinin titer at that time was 1280 . Sulfadiazine was given later and the anemia improved during this therapy. In the other 3 patients, including the earliest case that was recognized, the anemia was first noted towards the end of the third week of a very severe illness in which almost the entire lung was affected. Sulfonamides had been given for several days in each instance. Sulfadiazine was used in one, sulfathiazole in another, and both drugs in the third. The first test for cold agglutinins was done in each instance after the anemia was established and the titers at that time were 640,1280 , and 5120 , respectively.

Some evidence for the hemolytic nature of the anemia was obtained in most of these cases. The drop in hemoglobin was usually accompanied by leukocytosis, with total white blood cell counts rising to 20,000 or higher. In some, the icterus index was later elevated and reticulocytosis was noted at that time.

Although these data are inadequate in many respects, they nevertheless suggest that the hemolytic anemias observed in these cases of primary atypical pneumonia were in some way related to the presence of cold agglutinins. While it cannot be denied that either sulfadiazine or sulfathiazole, the drugs used in these cases, may under certain circumstances themselves be responsible for the occurrence of acute hemolytic anemia, the evidence in the present cases suggests that these drugs were probably not the cause of the anemia nor did their administration appear to aggravate the condition when it occurred.

\section{DISCUSSION}

It was the main purpose of this paper to characterize the relationship of cold agglutinins to atypical pneumonia. The time in the disease when they make their appearance and the course of the cold agglutinins are suggestive of an antibody response as has been postulated $(14,15)$. In that event, it must be assumed that the antigen 
involved is in some way related to the etiological agent of the disease or to the products of its action on the human body during the course of the infection. This hypothesis is consistent with the correlation of the high titers with the severity of the disease, the extent of the pulmonary lesions, duration of the fever, and also with the more frequent findings of cold agglutinins in patients who had elevated leukocyte counts.

A number of the properties of the hemagglutinins in some of these cases were studied. They were found to be similar to others described $(12,14$ to 16$)$. Certain of these findings and a consideration of some of the features of the test for cold agglutinins will be presented in subsequent papers.

Agglutinins for streptococcus 344 (5) were noted in connection with the findings in some of the representative cases presented in the text and in Figues 3 to 6 . Almost all of the patients with atypical pneumonia who had cold agglutinins in significant titers were also found to have agglutinins for this strain of streptococcus. The details of these findings will be considered elsewhere. The findings are of interest because they suggest that there is also an antigen in this streptococcus which is in some way related to the etiologic agent in the present cases.

An alternative hypothesis concerning the nature of the cold agglutinins in primary atypical pneumonia might be considered. This hypothesis would attribute to the unknown virus of this disease, 2 characteristics which are common to some, and possibly to many other viruses. The first is the property of certain virus particles or their soluble products to agglutinate human erythrocytes and those of other animal species, as exemplified by the agglutination of the erythrocytes of fowl, of humans, and of other animal species by the various known types of influenza virusthe now well known Hirst phenomenon. The other is the common property of certain viruses to persist in the body of the host for long periods after all evidence of active infection has disappeared. On the basis of these 2 properties of viruses, one might assume that the cold agglutinin is the result of the interaction of red blood cells with the virus or its products.

This hypothesis would seem to be inconsistent with the fact that cold agglutinins do not appear until several days after the onset of symptoms. On the other hand, if it is correct, one could assume that virus activity takes place and causes infection in some part of the body for several days before the virus particles or their products are discharged into the circulation. Such an hypothesis would be consistent with the increase in the titer of cold agglutinins towards the end of the disease. It would also be consistent with the rapid drop in titer and the early disappearance of the cold agglutinins in most of the cases. In addition, it would account for the high titers observed in the severe cases and the persistence of the cold agglutinins in many such cases. Clinically, it is known that some of the severe cases of primary atypical pneumonia are followed by symptoms which persist for a long time and suggest continued infection. Notable are the asthmatic-like attacks which in occasional cases occur for several weeks after the acute disease has subsided. These attacks and the lassitude and general weakness which are common after severe attacks, may be the results of persistent low grade infection.

The mechanism of the anemia in the present cases is of interest. It occurred in each case after the middle of the second week of the acute disease at a time when maximum titers of cold agglutinins are most often encountered. The anemia was apparently independent of sulfonamide therapy and not affected by it. The mechanism of its occurrence is a matter for speculation. From the results of in vitro studies by others (17 to 19), the agglutination of erythrocytes renders them more susceptible to hemolysis when subjected to mechanical stimuli. On the basis of their observations, certain of these authors (19) also suggest that cohesion of erythrocytes may lead to their increased mechanical destruction while in motion in the circulation. Their observations have shown this condition to occur in the presence of isoagglutinins and cold agglutinins and with sickled cells. Further unpublished studies by Ham, in a patient with cold agglutinins who had a negative Donath-Landsteiner test, indicated that hemoglobinemia could be produced by exposure of a limb to the cold. In patients with atypical pneumonia, particularly during the height of the disease and in severe cases, there may be transient reduction in the skin temperature, especially of the extremities. This may occur during chills 
or as a result of exposure or of the administration of antipyretics. In patients with marked cold autoagglutination, there is usually a wide thermal range and significant agglutination may still occur at the temperatures which are attained in the skin of the extremities under such conditions. This might conceivably represent the conditions under which hemolysis might occur through the mechanism suggested above (19).

Tests for autohemagglutination unfortunately were not carried out in many of the cases. In the few that were done in this study and by others (15), there was essential agreement between the autohemagglutinin and the isohemagglutinin titers. There is reason to believe, however, that in certain of the patients with atypical pneumonia, autohemagglutinins may develop and not be demonstrable by the tests for isohemagglutinins-that is, with the use of erythrocytes from other donors. An example of such a case which was complicated by a hemolytic anemia was presented. Similar observations were made in one other case without hemolytic anemia in which agglutination of the patient's own cells was marked and occurred in high titers but could not be demonstrated by the method used in the tests which employed cells from other donors. This suggests the possibility that the antigen responsible for the cold agglutinins may be related directly to the tissues of the infected patient.

\section{SUMMARY AND CONCLUSIQNS}

An analysis has been presented of the results of tests for cold isohemagglutinins in 200 characteristic cases of primary atypical pneumonia of unknown etiology which occurred between September 1942 and January 1944. On the basis of these findings, the relation of the cold isoagglutinin to atypical pneumonia may be characterized as follows:

Cold agglutinins are absent early in the disease. They usually make their appearance during the second or third week after the onset of symptoms and the titers increase rapidly thereafter. The maximum titers are attained in most instances between the middle of the second and the middle of the fourth weeks. The height of the maximum titer appears to be unrelated to the time when it is attained. The titers drop fairly rapidly after reaching the maximum so that significantly lower ones are already found between the third and fifth weeks. In most of the cases, the cold agglutinins can no longer be demonstrated in a significant titer by the fourth to the sixth weeks. Significant titers persist longer in cases in which the maximum titers are very high.

The maximum titers observed by the method employed ranged from 10 to 10,000 . In most instances, the highest observed titers were between 40 and 1280. The height to which the cold agglutinin titers rose was related in a general way to the severity of the symptoms, to the extent of the pulmonary lesion, and to the duration and height of the fever. The maximum titers were also somewhat higher in cases in which there was a leukocytosis during some part of the acute disease, usually during the latter part of the febrile course. The height to which the cold agglutinin titer rose was unrelated to the age of the patient, the administration of sulfonamides, or the time of year when the case occurred.

Some of the relevant findings in 11 cases of hemolytic anemia of varying severity which occurred among these 200 cases of atypical pneumonia were presented. The relation of the anemia to the cold agglutinins and to sulfonamide therapy was discussed. It was suggested that under certain circumstances agglutination may occur in the peripheral circulation. The agglutinated erythrocytes are then subjected to mechanical destruction and thus give rise to hemolysis and anemia.

The authors are indebted to the many physicians, both at the Boston City Hospital and in other hospitals, who permitted them to observe the patients under their care and to obtain the blood for these studies as well as the clinical and laboratory data for this analysis. They are also grateful to Dr. T. Hale Ham and Miss Geneva A. Daland for carrying out some of the observations in the cases of hemolytic anemia. Mrs. Muriel B. Stone rendered technical assistance during part of this study.

\section{BIBLIOGRAPHY}

1. Finland, M., Peterson, O. L., Allen, H. E., and Samper, B. A., Cold agglutinins. I. Occurrence of cold isohemagglutinins in various conditions. $\mathrm{J}$. Clin. Invest., 1945, 24, 451.

2. Peterson, O. L., Ham, T. H., and Finland, M., Cold agglutinins (autohemagglutinins) in primary atypical pneumonias. Science, 1943, 97, 167.

3. Official Statement. Primary atypical pneumonia, etiology unknown. War Med., 1942, 2, 330. 
4. Dingle, J. H., and Finland, M., Virus pneumonias. II. Primary atypical pneumonias of unknown etiology. New England J. Med., 1942, 227, 378.

5. Thomas, L., Mirick, G. S., Curnen, E. C., Ziegler, J. E., Jr., and Horsfall, F. L., Jr., Serological reactions with an indifferent streptococcus in primary atypical pneumonia. Science, 1943, 98, 566.

6. Finland, M., Samper, B. A., and Barnes, M. W., Cold agglutinins. VI. Agglutinins for an indifferent streptococcus in primary atypical pneumonia and in other conditions and their relation to cold isohemagglutinins. J. Clin. Invest., 1945, 24, 497.

7. Reimann, H. A., Primary atypical pneumonias of unknown cause: "Virus" or "Viral" pneumonias. Case report of a similar disease without pneumonia. J. Michigan M. Soc., 1944, 43, 147.

8. Boyer, N. H., Acute hemolytic anemia following sulfadiazine. Report of a case. New England J. Med., 1943, 228, 566.

9. Nickum, J. S., A case of cold agglutination of own serum, treated by heparin intravenously. Connecticut M. J., 1943, 7, 475.

10. Dameshek, W., Cold hemagglutinins in acute hemolytic reactions in association with sulfonamide medication and infection. J. A. M. A., 1943, 123, 77.

11. Layne, J. A., and Schemm, F. R., Acute macrocytic hemolytic anemia occurring following administra- tion of sulfadiazine. J. Lab. and Clin. Med., 1944, 29, 347.

12. Clough, M. C., and Richter, I. C., A study of an autoagglutinin occurring in a human serum. Bull. Johns Hopkins Hosp., 1918, 29, 86.

13. Wheeler, K. M., Gallagher, H. J., and Stuart, C. A., An unusual case of autoagglutination. J. Lab. and Clin. Med., 1939, 24, 1135.

14. Turner, J. C., and Jackson, E. B., Serological specificity of an auto-antibody in atypical pneumonia. Brit. J. Exper. Path., 1943, 24, 121.

15. Turner, J. C., Nisnewitz, S., Jackson, E. B., and Berney, R., Relation of cold agglutinins to atypical pneumonia. Lancet, 1943, 1, 765.

16. Stats, D., and Wasserman, L. R., Cold hemagglutination-an interpretive review. Medicine, 1943, 22, 363.

17. Stats, D., Cold agglutinated erythrocytes: hemolytic effect of shaking. Proc. Soc. Exper. Biol. and Med., 1943, 54, 305.

18. Lee, J., Puh, Y. C., and Tsai, C., Observations on the development of hemolytic anemia induced by concanavalin. Proc. Chinese Physiol. Soc., Chengtu Branch, 1944, 2, 59.

19. Shen, S. C., Castle, W. B., and Fleming, E. M., Experimental and clinical observations on increased mechanical fragility of erythrocytes. Science, 1944, 100, 387. 